\title{
Role of Coronary Angiography in Myxoma Patients: A 14-Year Experience in One Medical Center
}

\author{
Ai-Hsien Li Chiau-Suong Liau Chau-Chung Wu Kuo-Liong Chien \\ Yi-Lwun Ho Chieng-Hua Huang Ming-Fong Chen Yuan-Teh Lee \\ Department of Internal Medicine, National Taiwan University Hospital, Taipei, Taiwan, ROC
}

\section{Key Words}

Myxoma $\cdot$ Coronary artery disease $\cdot$ Coronary

angiography

\begin{abstract}
Cardiac myxoma is the most common form of primary heart tumor and often treated with surgical resection without a preoperative angiographic examination for fear of potential risk of sudden death. During the last 14 years, 24 of 38 patients with myxoma underwent coronary angiography. Coronary artery disease (CAD) and other abnormalities were found in 5 . Our findings indicated that CAD is not uncommon among the myxoma patients, and coronary angiography should be performed preoperatively in all cases.
\end{abstract}

Copyright $\odot 2000$ S. Karger AG, Basel

Cardiac myxoma is the most common primary cardiac tumor, accounting for about $50 \%$ of cardiac tumors [1]. However, it is still relatively uncommon, appearing in only $0.0017-0.33 \%$ of autopsy series [1]. Nowadays, myxoma can be easily diagnosed by echocardiography and almost cured by surgical resection. Therefore, some authors proposed to resect a myxoma as soon as it is detected, even without preoperative angiography [1-4], because of its potential risk of sudden cardiac death after

\begin{tabular}{ll}
\hline KARGER & ○ 2000 S. Karger AG, Basel \\
Fax +4161306 1234 & 0008-6312/99/0924-0232\$17.50/0 \\
$\begin{array}{l}\text { E-Mail karger@karger.ch } \\
\text { www.karger.com }\end{array}$ & $\begin{array}{l}\text { Accessible online at: } \\
\text { www.karger.com/journals/crd }\end{array}$
\end{tabular}

mitral annular obstruction. In the past, there were very limited reports on the association of coronary artery disease (CAD) and myxoma. It is important to detect this counterpart association of CAD with cardiac tumor, because simultaneous coronary artery bypass surgery would be crucial to the patients with critical coronary lesions. The aims of this study were to investigate the coronary condition and to estimate the prevalence rate of coronary artery disease among patients with cardiac myxoma.

\section{Patients and Methods}

Between 1984 and 1998, a total of 38 patients ( 24 women and 14 men, aged 21-81 years) were diagnosed to have cardiac myxoma by echocardiography at the National Taiwan University Hospital. We excluded 3 patients, 2 died of other diseases and 1 with poor lung function. The remaining 35 patients received surgical resection with a definite pathological diagnosis of myxoma. Only 24 patients received preoperative coronary angiography. CAD was defined as $>70 \%$ stenosis in the left anterior descending artery (LAD), left circumflex artery (LCx), and right coronary artery (RCA) and $>50 \%$ stenosis in the left main coronary artery (LM).

We divided the myxoma patients into two groups (with/without CAD) and correlated the prevalence rate of CAD risk factors. The $\chi^{2}$ test was used to test the correlation. The risk factors were defined according to guidelines of the National Cholesterol Education Program $[5,6]$.

Z-approximation was used to compare the CAD rate of our patients with that reported in a previous study of a Chinese population [7].
Yuan-Teh Lee, MD
Department of Internal Medicine, National Taiwan University Hospital
No. 7, Chung-Shan South Road
Taipei, Taiwan (ROC) 
Table 1. Characteristics of the myxoma patients undergoing coronary angiography (1984-1997) by timing sequence

\begin{tabular}{|c|c|c|c|c|c|c|c|c|c|}
\hline & Sex & $\begin{array}{l}\text { Age } \\
\text { years }\end{array}$ & Symptom 1 & Symptom 2 & Symptom 3 & $\begin{array}{l}\text { Chest } \\
\text { pain }\end{array}$ & $\begin{array}{l}\text { CAD risk } \\
\text { factors }\end{array}$ & CAD & $\begin{array}{l}\text { Feeding } \\
\text { artery }\end{array}$ \\
\hline 1 & $\mathrm{~F}$ & 36 & DOE & palpitation & & - & 1 & - & RCA/LCx \\
\hline 2 & $\mathrm{~F}$ & 61 & orthopnea & palpitation & blindness & - & 3 & - & $\mathrm{LCx}$ \\
\hline 3 & M & 57 & DOE & & & - & 2 & - & \\
\hline 4 & $\mathrm{~F}$ & 42 & DOE & syncope & & - & 0 & - & \\
\hline 5 & $\mathrm{~F}$ & 35 & DOE & & & - & 0 & - & RCA \\
\hline 6 & $\mathrm{~F}$ & 51 & palpitation & dizziness & & - & 1 & - & $\mathrm{LCx}$ \\
\hline 7 & M & 57 & DOE & palpitation & & - & 4 & - & \\
\hline 8 & $\mathrm{~F}$ & 46 & DOE & palpitation & & - & 0 & 1VD (LAD) & RCA \\
\hline 9 & M & 67 & DOE & orthopnea & chest pain & + & 3 & - & $\mathrm{LCx} / \mathrm{RCA}$ \\
\hline 10 & $\mathrm{~F}$ & 48 & DOE & palpitation & & - & 2 & - & \\
\hline 11 & M & 50 & DOE & & & - & 3 & - & RCA/LCx \\
\hline 12 & $\mathrm{~F}$ & 41 & palpitation & & & - & 0 & - & LCx \\
\hline 13 & $\mathrm{~F}$ & 60 & DOE & & & - & 2 & - & LCx \\
\hline 14 & $\mathrm{~F}$ & 36 & DOE & dizziness & & - & 0 & - & $\mathrm{RCA}$ \\
\hline 15 & $\mathrm{~F}$ & 44 & DOE & PND & chest pain & + & 0 & LAD bridging & \\
\hline 16 & $\mathrm{~F}$ & 59 & DOE & chest pain & & + & 3 & - & $\mathrm{LCx}$ \\
\hline 17 & M & 58 & DOE & & & - & 3 & 2VD (LAD, RCA) & \\
\hline 18 & M & 81 & chest pain & & & + & 4 & $2 \mathrm{VD}$ (LM, RCA) & \\
\hline 19 & M & 69 & & & & - & 3 & $3 \mathrm{VD}$ & \\
\hline 20 & $\mathrm{~F}$ & 21 & palpitation & dizziness & & - & 0 & - & \\
\hline 21 & M & 55 & DOE & palpitation & & - & 4 & - & \\
\hline 22 & M & 65 & DOE & PND & syncope & - & 3 & - & \\
\hline 23 & M & 45 & chest pain & & & + & 2 & $3 \mathrm{VD}$ & \\
\hline 24 & $\mathrm{~F}$ & 47 & chest pain & & & + & 1 & - & \\
\hline
\end{tabular}

$\mathrm{DOE}=$ Dyspnea on exertion; PND = paroxysmal nocturnal dyspnea; $2 \mathrm{VD}=$ two-vessel disease; $3 \mathrm{VD}=$ triplevessel disease.

\section{Results}

In our 38 patients, the myxoma was located in the right atrium in 4 , in the left ventricle in 1 and in the left atrium in 33 patients. The major clinical manifestations of the 24 patients subjected to preoperative coronary study were listed in table 1 according to the timing sequence. The most common symptom was exertional dyspnea (16/24, $66.7 \%)$, followed by palpitation $(9 / 24,37.5 \%)$, chest pain $(6 / 24,25 \%)$, dizziness $(3 / 24,12.5 \%)$, and syncope $(2 / 24$, $8.3 \%)$. Among our patients, 5 had CAD, i.e. the prevalence rate was $20.8 \%$, which is strikingly higher than the percentage in the general population studied previously $(\mathrm{p}<0.05)$ [7]. Besides, another patient has myocardial bridging over LAD and atypical angina (table 2). One of the CAD patients had a discrete LAD stenosis, which was proved to result from a myxoma thrombus pathologically. The other 4 patients had multiple vessel diseases. None of the patients with CAD was disclosed to have left ventricular regional wall motion abnormality by echocardiogra-

Role of Coronary Angiography in Myxoma Patients phy. In the 24 patients, 11 had angiographically defined tumor-feeding arteries, 3 from the RCA, 5 from the LCx, and 3 from both the RCA and LCx (table 1). All the CAD patients received coronary artery bypass grafting.

We compared the prevalence rate of CAD risk factors between the CAD and non-CAD groups, and no statistic discrepancy in age, hypertension, smoking habits, diabetes or hyperlipidemia was found between these two groups (table 3).

\section{Discussion}

Cardiac myxoma is rare and presents with a triad of obstructive, embolic, and constitutional symptoms [1,9]. Some authors also reported malignant characteristics such as local invasion and metastasis [1, 10-12]. Myxoma may not only lead to distal embolization but also to mitral valve obstruction, which can occur at any time and precipitate sudden death [3]. Besides, it can be diagnosed eas- 
Table 2. Clinical characteristics of the myxoma patients with coronary abnormalities

\begin{tabular}{llllllll}
\hline $\begin{array}{l}\text { Age } \\
\text { years }\end{array}$ & Sex & Symptom & Symptom & $\begin{array}{l}\text { Chest } \\
\text { pain }\end{array}$ & $\begin{array}{l}\text { CAD risk } \\
\text { score }\end{array}$ & Coronary condition & Operation \\
\hline 46 & F & DOE & palpitation & - & 0 & $\begin{array}{l}\text { LAD dicrete lesion } \\
\text { resulting from thrombus }\end{array}$ & $\begin{array}{l}\text { excision + LAD } \\
\text { thrombectomy } \\
\text { excision }\end{array}$ \\
44 & F & DOE & chest pain & + & 0 & LAD middle bridging & excision + CABG \\
61 & M & DOE & & - & 3 & 2VD: LAD + RCA & excision + CABG \\
81 & M & angina & & + & 5 & 2VD: D1 + RCA & excision + CABG \\
69 & M & & - & 3 & 3VD: LM + LCx + RCA & excision + CABG \\
45 & M & angina & & + & 2 & 3VD: LAD + OM + RCA & (2) \\
\hline
\end{tabular}

D1 = First diagonal branch of LAD; OM = obtuse marginal artery; $\mathrm{DOE}=$ dyspnea on exertion; $\mathrm{LABG}=$ coronary artery bypass graft.

Table 3. Prevalence of CAD risk factors in the myxoma patients

\begin{tabular}{|c|c|c|c|c|c|}
\hline \multirow[t]{2}{*}{$\begin{array}{l}\text { CAD risk } \\
\text { factors }\end{array}$} & \multicolumn{2}{|c|}{$\begin{array}{l}\text { CAD patients } \\
(\mathrm{n}=5)\end{array}$} & \multicolumn{2}{|c|}{$\begin{array}{l}\text { Non-CAD } \\
\text { patients }(\mathrm{n}=13)\end{array}$} & \multirow[t]{2}{*}{$\chi^{2}$ test } \\
\hline & $\%$ & $\mathrm{n}$ & $\%$ & $\mathrm{n}$ & \\
\hline Age & 60 & 3 & 63 & 12 & $\mathrm{p}>0.05$ \\
\hline Gender & 80 & 4 & 36 & 7 & $\mathrm{p}>0.05$ \\
\hline Smoking & 80 & 4 & 26 & 5 & $\mathrm{p}>0.05$ \\
\hline Hypertension & 20 & 1 & 5.2 & 1 & $\mathrm{p}>0.05$ \\
\hline Hyperlipidemia & 20 & 1 & 21 & 4 & $\mathrm{p}>0.05$ \\
\hline Diabetes & 0 & 0 & 5.2 & 1 & $\mathrm{p}>0.05$ \\
\hline
\end{tabular}

ily by echocardiography and cured by surgical intervention with low risk [2]. Therefore, some authors proposed that surgery should be performed as soon as echocardiographic examination has confirmed the diagnosis, and preoperative catheterization is not necessary [1-4]. In cases of syncope or embolic event, even emergency surgery may be considered [2]. However, such strategy prevents the detection of the coexisting CAD.

To the best of our knowledge, there are only five studies in the literature investigating the relationship between CAD and myxoma [8, 9, 13-15] (table 4). Most of those studies showed prevalence rates of CAD in myxoma patients of $0-11 \%$, and only the study performed by Fueredi et al. [9] yielded a very high $(6 / 9,66.7 \%)$ rate. If the prevalence rate of CAD in the myxoma patients were as low as in these studies, it would be reasonable to skip the catheterization and go directly to surgery once myxoma is diagnosed by echocardiography. Actually, Cleemput et al. [8] proposed that coronary angiography was only indicated in patients with a previous myocardial infarction or with clear history of angina. Our study had a bigger sample size and revealed a much higher prevalence rate than those previously reported. We did not have much evidence in the literature to answer whether such a higher rate resulted from ethnical differences, i.e. if Chinese patients with myxoma had a higher CAD prevalence. However, compared with the previously reported CAD prevalence $(9.41 \%, 673 / 7,159)$ in one autopsy study in a Chinese population [7], our myxoma patients still have a strikingly higher CAD rate $(\mathrm{p}<0.001)$. Besides, from one of our unpublished epidemiological studies in Northern Taiwan which has enrolled 3,602 persons since 1991, the prevalence rate of CAD in Taiwan was only about $3 \%$, which is still much lower than that of our myxoma patients.

What made the prevalence rate of CAD in our myxoma patients so high? Do they have more CAD risk factors? However, there is no significant difference in risk factor distribution in our study between the CAD and the non-CAD groups statistically, i.e. even though we considered the presence of CAD risk factors, it is still hard to know exactly before catheterization whether a myxoma patient would have CAD or not. Actually, even patients without any risk factor would have CAD (patient 8). Therefore, every patient with myxoma might need coronary angiography to rule out CAD before operation.

Why did so many myxoma patients have CAD? Just as 1 of our 5 patients, embolization of myxoma fragments could occur in the coronary system. In a study by Silverman et al. [16], 3 of the 35 myxoma patients with system embolization had the emboli in the coronary system. Balk et al. [17] reported chronic coronary embolization of myxoma led to vessel narrowing and aneurysm dilatation, which was similar to the findings of cerebral, renal, and 
Table 4. Previous studies of myxoma and CAD

\begin{tabular}{|c|c|c|c|c|c|}
\hline \multirow[t]{2}{*}{ Authors } & \multirow{2}{*}{$\begin{array}{l}\text { Year of } \\
\text { publication }\end{array}$} & \multirow[t]{2}{*}{ Patients } & \multicolumn{2}{|c|}{ CAD } & \multirow[t]{2}{*}{ Feeding artery } \\
\hline & & & $\mathrm{n}$ & $\%$ & \\
\hline Salcedo et al. [13] & 1983 & 18 & 1 & 5.5 & not defined \\
\hline Fueredi et al. [9] & 1989 & 9 & 6 & 67 & $\begin{array}{l}3 \text { from RCA, } 1 \text { from } \\
\text { LCx, } 1 \text { from both }\end{array}$ \\
\hline Chow et al. [14] & 1991 & 9 & 0 & & $\begin{array}{l}2 \text { from } L C x, 1 \text { from RCA } \\
\text { and } L C x\end{array}$ \\
\hline Shimono et al. [5] & 1992 & 7 & 0 & & not defined \\
\hline Cleemput et al. [8] & 1993 & 19 & 2 & 10.5 & 4 from RCA, 3 from $L C x$ \\
\hline
\end{tabular}

pulmonary vessels. Acute myocardial infarction might result from coronary embolization $[15,18-21]$. Besides, Isobe et al. [22] reported that 3 myxoma patients had elevated levels of interleukin-6 and interleukin-8, which would induce a hypercoagulable state and induce coronary thromboembolism. Therefore, our myxoma patients might be under a higher risk of coronary embolism and cytokine-related thrombosis, which would lead to CAD afterwards.

\section{Conclusion}

CAD was more prevalent in the patients with myxoma than in the general population. This implies that coronary angiographic examination must be performed before surgical resection to detect coexistent CAD.

\section{References}

1 Markel ML, Waller BF, Amstrong WF: Cardiac myxoma, a review. Medicine 1987;66:114125 .

2 Castells E, Ferran V, Toledo MCOD, Calbet JM, Benito M, Fontanillas C, Granados J: Cardiac myxomas: Surgical treatment, long-term results and recurrence. J Cardiovasc Surg 1993; 34:49-53.

3 Thomas KE, Winchell CP, Varco RL: Diagnosis and surgical aspects of left atrial tumors. $\mathbf{J}$ Thorac Cardiovasc Surg 1967;53:535-548.

4 Sutton MGJ, Mercier LA, Giuliani ER, Lie JT: Atrial myxomas - A review of clinical experience in 40 patients. May Clin Proc 1980;55: 371-376.

5 Shimono T, Komada T, Kusagawa H, Shiapo H, Yada I, Yuasa H, Kusagawa M, Takeuchi Y, Yamazaki Y, Takigawa K: Left atrial myxomas: Clinical characteristics, evaluation and considerations in classifying tumors. Nippon Kyobu Geka Gakkai Zasshi 1992;40:10601066.

6 Summary of the Second Report of the National Cholesterol Education Program (NCEP) Export Panel on Detection, Evaluation and Treatment of High Cholesterol in Adults (Adult Treatment Panel II). JAMA 1993;269:30153024.

7 Coordination Group in China: A pathological survey of atherosclerotic lesions of coronary artery and aorta in China. Pathol Res Pract 1985; 180:456-462.
8 Cleemput JV, Daenan W, Geest HD: Coronary angiography in cardiac myxomas: Finding in 19 consecutive cases and review of the literature. Cathet Cardiovasc Diagn 1993;29:217220.

9 Fueredi GA, Knechtges TE, Czarnecki DJ: Coronary angiography in atrial myoma: Findings in nine cases. AJR 1989;152:737-738.

10 Ng HK, Poon WS: Cardiac myxoma metastasizing to the brain. J Neurosurg 1990;72:295298.

11 Diflo T, Cantelmo NL, Haudenschid CC, Watkins MT: Atrial myxoma with remote metastasis and review of the literature. Surgery 1992 ; 111:352-356.

12 Attum AA, Johnson GS, Masri Z, Girardet R, Lansing AM: Malignant clinical behavior of cardiac myxoma and 'myxoid imitators'. Ann Thorac Surg 1987;44:217-222.

13 Salcedo EE, Adams FKV, Lever HM, Gill CC, Lombardo $\mathrm{H}$ : Echocardiographic findings in 25 patients with left atrial myxoma. J Am Coll Cardiol 1983;1:1162-1166.

14 Chow WH, Chow TC, Tai YT, Yip ASB, Cheung KL: Angiographic visualization of 'tumour vascularity' in atrial myxoma. Eur Heart J 1991;12:79-82.
15 Hashimoto H, Takahashi H, Fujiwara Y, Joh $\mathrm{T}$, Tomino T: Acute myocardial infarction due to coronary embolization from left atrial myxoma. Jpn Circ J 1993;57:1016-1020.

16 Silverman J, Olwin JS, Graettinger JS: Cardiac myxomas with systemic embolization. Review of the literature and report of a case. Circulation 1962;26:99-103.

17 Balk AHM, Wagenaar SS, Bruschke AVG: Bilateral cardiac myxomas and peripheral myxomas in a patient with recent myocardial infarction. Am J Cardiol 1979;44:767-770.

18 Abascal VM, Kasznica J, Aldena G, Davidoff $\mathrm{R}$ : Left atrial myxoma and acute myocardial infarction - A dangerous duo in the thrombotic agent era. Chest 1996;109:1106-1108.

19 Romisher SC, Cannon LA, Davakis N: Atrial myxoma associated with inferior myocardial infarction. Ann Emerg Med 1991;20:12361238.

20 Lehrman KL, Prozan GB, Ullyot D, Calif B: Atrial myxoma presenting as acute myocardial infarction. Am Heart J 1985;110:1293-1295.

21 Tanabe J, Williams RL, Diethrich EB: Left atrial myxoma: Association with acute coronary embolization in an 11-year-old boy. Pediatrics 1979;63:778-781.

22 Isobe N, Kanda T, Sakamoto H, Morishita Y, Suzuki T, Kobayashi I: Myocardial infarction in myxoma patients with normal coronary arteries. Angiology 1996;47:819-823. 
Copyright: S. Karger AG, Basel 1999. Reproduced with the permission of S. Karger AG, Basel. Further reproduction or distribution (electronic or otherwise) is prohibited without permission from the copyright holder. 